\title{
Entre o velho, 0 atual e o inédito: para quem serve a história?
}

\section{Camilla Cristina Silva}

Universidade Federal 'de Ouro Preto (UFOP)

\section{Resumo}

Vivenciamos um presente enredado pela marca espectral do passado. Passado que é presença para atingidos direta e indiretamente pela violência, que por um tempo foi emudecedora. Passado que é ausência, sobre o qualé impossível agir ou mesmo fazer justiça, para a historiografia. Entre os caminhos da justiça de transição e da escrita da história profissional o artigo intenta em vez de responder, provocar: para quem serve a história?

Palavras-chave: Historiografia; Justiça de transição; Ausência e presença do passado.
Between the old, the present and the unprecedented: who is the history for?

\begin{abstract}
We experience an entangled present by the spectral mark of the past. Past that is presence for the the directly and indirectly affected by violence, that was silencer for a while. Past that is absence, over which it is impossible to act or even do justice, for historiography. Between the paths of transitional justice and the writing of professional history the paper aims rather than answer, provoke: Who is the history for?
\end{abstract}

Keywords: Historiography; Transitional justice; Absence and presence of the past. 


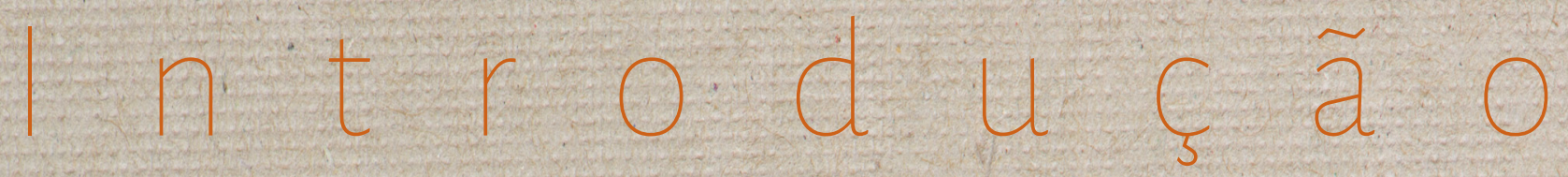

[o tempo é] esse tempo. Ou perto dele. Um tempo depois de outro tempo.

Em camadas. De acordo com o sentido que se dá aos sentidos do tempo.

Como se alguém pudesse explicar uma coisa dessas.

Prova contrária, de Fernando Bonassi (2003).

A discussão sobre o tempo histórico não é nova na historiografia. Remonta aos primórdios da construção coletiva do conceito de história, no século XVIII, quando a elaboração da experiência se torna possível com o advento de um tempo inédito descoberto pela história. É através da história que a ordenação da experiência assume uma distância cada vez maior da própria experiência, ou seja, do passado. Nos últimos anos, estes debates concentram questões sobre políticas do tempo, tanto do ponto de vista de contestação epistemológica da historiografia, quanto da contradição entre o tempo da memória e o da história, e da relação entre história profissional e história não acadêmica.

O século XX trouxe estímulos - catastróficos - para o processo de reelaboração de sentidos na relação entre homem, sociedade, arte, ciência, espaço e tempo. Dar sentido ao presente depois da aniquilação da ontologia do humano pela Shoah, do Apartheid na África do Sul, da sistematização e generalização do desaparecimento forçado pelas ditaduras latino-americanas, dos genocídios em Ruanda e ná Cuatemala, manifesta como uma colcha de retalhos tecida a mãos discordantes, confluentes, inúmeras e únicas. Na complexidade do indizível e no dever de ser dito, naquilo que Fernando Bonassi (2003, p. 25) bem descreveu: "Como se alguém pudesse explicar uma coisa dessas....

São tentativas, responderíamos a Bonassi: Seu próprio trabalho é uma tentativa de explicar o tempo instituído pelo trauma, pela ausência de vida e pela presença fantasmagórica do passado dado como morto por uma 
lei. Tentativas vitais para a reordenação das categorias do tempo. Ou o que Sérgio Buarque de Holanda (apud PEREIRA \& SANTOS, 2013, p. 14) cunhou como estudos históricos em seu artigo publicado no jornal Correio da Manhã. em 1951, categoria que reúne "toda a produção nas diferentes áreas da história, ou que se valem da história, ou que repercutem sobre esta".

Para o estudo de passados recentes, a abordagem de Sérgio Buarque fornece uma justificativa para a convivência (e concorrência) de diferentes discursos. Este artigo também é uma tentativa de pensar divergências e convergências nas formas de lidar com passados - ou melhor, nas formas de lidar com categorias ontológicas do tempo que possuem características análogas de rupturas institucionais- e políticas, de coordenação repressiva e violência estatal. Dentre a variedade de respos-

1 O livro de Bonassi (2003) é escrito como uma encenação de uma aporia que reúne três personagens: o narrador, a mulher e o homem. A mulher convive com a presença fantasmagórica do homem, desaparecido, agora morto; e do tempo, da espera, agora encerrado. O delinear da narrativa fragmentada espaço e temporalmente é construído a partir da Lei $n^{\circ} 9.140$, de 1995 , através da qual eram consideradas mortas as pessoas desaparecidas, ali listadas, por agentes do Estado brasileiro no período entre 1961 e 1988. Entre presença do passado, que especialmente os crimes de desaparecimento produzem, e ausência, no encerramento através da morte, Bonassi constrói uma narrativa lancinante, assim como imaginamos ser a experiência das pessoas diretamente atingidas pela ausência e presença constante e ensurdecedora, da vida e da morte. tas às ditaduras latino-americanas, há uma linha nada tênue que demarca as manifestações destes eventos no decorrer dos anos. Emanados de diversos domínios profissionais e sociais, estudos históricos que versam sobre os processos de transição para a democracia na América Latina compreendem temporalidades que ora subvertem, ora reatualizam o conceito de e o projeto da História. Fortalecem o dissenso, acendem o conflito entre o que entendemos por diferentes regimes de temporalidades ${ }^{2}$.

\section{Políticas do tempo: o passado recente entre a história e o direito}

Diante de todo dissenso sobre os passados recentes latino-americanos e sua carga residual no presente, pare-

2 Ao usar o conceito regimes de temporalidades, nos afastamos dos conceitos de regimes de historicidade e estratos do tempo, cunhados e referenciados por François Hartog (2013) e Reinhart Koselleck (2014). Em nossa percepção, ambos os conceitos não permitem uma análise das formas de relacionamento com o tempo para além da historiografia, pela vinculação que ambo's autores fazem, em seus estudos, entre o tempo e o tempo da história. Apesar da importância destas reflexões, que estão na base epistemológica desta pesquisa, pensar em regimes de temporalidades nos permite ir além dos limites da historiografia, no intuito de explicar como memória, história e justiça, ao lidarem com passados recentes marcados por graves violações, ordenam as categorias temporais. 
ce haver ao menos dois consensos bem estabelecidos, fora e dentro do campo historiográfico: fora, a noção de que a importância do envolvimento de historiadores está na sua capacidade de fixar o passado como de fato foi, de forma imparcial; dentro, e que atinge também a filosofia e o direito, a separação dos trabalhos do historiador e do juiz. Antoine Garapon, jurista francês, transmite com clareza estes entendimentos em seu livro sobre as possibilidades da justiça penal internacional frente aos crimes contra a humanidade. Em sua reflexão sobre fazer justiça ao passado, Carapon (2004, p. 166) define os papéis e encontros entre o juiz e o historiador:

tanto o historiador como o juiz pretendem estabelecer o que se passou, mas com finalidades diferentes [...]. O historiador procura estabelecer um juízo de realidade sobre factos coletivos [...] [e deve] adoptar uma estrita neutralidade axiológica, isto é, abster-se de qualquer juízo de valor. Totalmente diferente é a perspectiva da justiça face ao passado: não é cognitiva, mas sim normativa (grifo do autor?).

O primeiro consenso, que transparece no início da afirmativa de Garapon, nos transporta à máxima de Leopold Von Ranke (apud BLOCH, 2001 , p. 125): "o historiador propõe apenas descrever as coisas tais como aconteceram"-fórmula veementemente contestada a partir de meados do século $X X$, quando autores como Marc Bloch e Lucien Febvre elaboraram problematizações sobre o fazer histórico e o papel do historiador como agente do saber que produz. Contrapondo-se à objetividade holística e à verdade metafísica, Bloch (2001, p. 55) contestaria: "onde calcular é impossível, impõe-se sugerir".

Todavia, mesmo que a discussão sobre haver algo de subjetivo no conhecimento produzido pelo historiador esteja presente desde o início das reflexões dos Annales, esta se limita ao tratamento dado às fontes e aos instrumentos de compreensão histórica disponiveis. Bloch (2001) era categórico ao responder a grande querela (julgar ou compreender?) que surgia com a aceitação de uma parcela de súbjetividade na análise histórica. Mas isso não significava admitir que o trabalho do historiador, ou seja, o trabalho do cientista, teria algo de parcial. 0 autor salienta duas formas de imparcialidade: a primeira, que se limitaria à observação e à compreensão, cara aos cientistas; e a segunda, que incluíria o juízo de valore determinaria a imparcialidade dos ju- 
ízes. A segunda não condiz com a primeira, nos termos de uma ciência positiva, como se compreende a história História é ciência, nesse momento não há contestação a essa assertiva; mas, uma ciência que não pode ser reduzida às leis e estruturas análogas das ciências naturais ${ }^{3}$. A verdade histórica dependeria de uma tríade: metodologia, análise crítica, imparcialidade.

\section{Apesar das transformações epistemo-} lógicas nas últimas décadas, esta tríade ainda é a base da historiografia. O trabalho historiográfico continua pautado na cientificidade, no reconhecimento pelos pares e na concordância de que a comunidade historiadora possui a capacidade de interpretar os fatos e de se relacionar com o tempo do alto de uma torre de marfim. Estas considerações derivam do que Hayden White (2017) define como a autoridade dos passados históricos, construída a partir do século XIX como forma sistemática de diferenciar o passado, revelado entre empiria e evidência, do ofício do historiador. O termo histórico, ao

3 É importante esta afirmação para nos referirmos ao estudo de Bloch, em Apologia da História. O autor busca reconstruir a utilidade da história, em contraposição à eventualidade do século XIX, mas pautando-se no cerne metodológico capaz de legitimar a história como ciência. Estamos cientes das divergências de abordagem para chegar a este fim, mas o que queremos ressaltar é o aprofundamento da noção de ciência e, consequentemente, das consequências dele para a disciplina, no movimento de renovação proposto pelos Annales. modificar o substantivo passado, atua em dois níveis: exclui qualquer tipo de passado não construído por historiadores profissionais e condensa o passado como exclusivamente histórico. Este é o fundamento da ideia do historicismo: nada além de passados que são autenticados pelo conhecimento histórico é passado (WHITE, 2011). Apesar das inúmeras críticas, contestações veementes e condenações, há algo audivel que permanece.

Basta lermos a entrevista recente com o historiador Manuel Lucena Giraldo (2016), publicada na revista História da Historiografia. Em uma discussão sobre história pública, Lucena constata que a consagração do trabalho pelos pares está condicionada à sua divulgação hos limites da academia. É recorrente a reprovação dentro da comunidade acadêmica a historiadoras e historiadores que saem da posição solar ${ }^{4}$, e empreendem o que é pejora-

4 A utilização do conceito remete aos trabalhos do historiador Valdei Araújo (2008), ao cunhá-lo para identificar o sujeito absoluto, produtor e comandante da realidade. Refere-se também às análises de Hans Cumbrecht (1998), especialmente em Cascatas da Modernidade, onde discute como a descoberta do Novo Mundo e a criação da imprensa possibilitam emergência da subjetividade ocidental e do observador de primeira ordem. Momento em que a centralidade do homem, como produtor de conhecimento, o difere do saber produzido, como um excêntrico, com desejo "puramente espiritual e de gênero neutro". O movimento na produção de saber seria, nesses termos, vertical - o sujeito interpreta o mundo a partir de um local privilegiado, acima do mundo das coisas e dos vivos, uma "posição solar". 
tivamente referido como vulgarização da história. Sobre a especialização e o constante distanciamento do conhecimento histórico dos passados práticos - conforme delineado por White (2011), passado útil à vida, que tem sido cada vez mais convocado no mundo contemporâneo -, o entrevistado ainda completa:

Acredito que houve um feísmo historiográfico - quanto pior escrevia, melhor historiador era - e, evidentemente, o senhor que compra um livro de história e não pode passar da primeira página [...] pode nos ensinar sobre algo que se rompe - e se rompe, talvez, de maneira definitiva (GIRALDO, 2016, p. 195) ${ }^{5}$.

Por outros caminhos, a permanência das considerações historicistas, construídas no momento em que o futuro era norteador da vivência e da representação, conflita de forma cada vez mais contundente com o tempo aberto pelos eventos da segunda metade do século XX. Não há futuro diante da desumanização do humano, após a catástrofe das guerras, dos genocídios. Não há futuro quando desmoro-

5 "Yo creo que hubo un feísmo historiográfico - cuanto peor escribías mejor historiador eras -y, evidentemente, el señor que compra un libro de historia y no puede pasar de la primera página [...] nos puede enseñar.sobre algo que se rompe y se rompe, quizás, de manera definitiva" (traduzido pela autora). na o projeto que encarna a esperança de um tempo vindouro. Não somente visões específicas de futuro ruíram, mas a própria categoria de futuro mudou destatus nas políticas do tempo.

Há uma inquietação entre historiadores e filósofos da história sobre como lidar com essa nova ordenação do tempo. Até onde podemos lidar com a mudança na relação entre passado, presente e futuro nos limites deontológicos da nossa formação? Aleida Assmann (2013) e Berber Bevernage (2008), cada qual a seu modo, diagnosticam o paradoxo entre a inerência das concepções modernas do tempo histórico e a fluidez fomentada pelo mundo da vida na modernidade. Ambos, amparados na concepção de breaking up time, trabalham com a questão da alteridade entre as categorias do tempo, construída e constantemente assumida pelos historiadores. Epistemologicamente, há uma pré- condição na historiografia moderna, pautada na capacidade de criar brechas e distâncias temporais.

Diante da violência perpetrada a partir de meados do século $X X$, a necessidade de conhecer o passado ganha 
uma qualidade quase febril do ponto de vista da história. Para Assmann (2013), nas últimas três décadas, a mudança na estrutura da temporalidade ocidental permitiu a religação entre espaço de experiência e horizonte de expectativas, nos termos do estabelecimento de uma relação de interdependência, em que o passado determina o futuro, mas também pode ser reavaliado à luz de outro futuro possível. 0 passado, nos caminhos da memória, seria uma carga que o presente carrega, e é este último que define o que esta carga significará para o futuro. A reivindicação por memória em contextos transicionais, que emergem no pós-1945 é, assim, ontologicamente distinta da flecha do tempo que translada em uma única direção irreversível. Dentro deste quadro temporal, o passado-apesar de nunca ter sido domínio exclusivo dos historiadores - é declaradamente reclamado em novas formas de lembrar, reconhecer e agir, que contestam o tempo da história (ASSMANN, 2013).

Bevernage (2008) reafirma constantemente em seu trabalho o caráter epistemológico do passado como ausente e distante, adotado pela historiografia ocidental. Nesses termos, esta catego- ria temporal é compreendida por sua dimensão ontológica inferior ao presente. O tempo da história é o tempo da irreversibilidade: o passado é passado, mesmo que injusto. Assim, a história não contempla, em suas análises, a possibilidade de fins reparativos, uma vez ser impossível compensarmos erros do passado.

Novas considerações sobre até onde vai o papel da história e do direito surgem nas experiências de justiça transicional. Em abordagem recente, Bervenage (2008) amplifica a existência do dissenso ao enfocar o conflito entre as concepções de tempo da história e tempo da justiça, tradicionalmente referenciado quanto à perspectiva respectivamente oposta entre ausência e presença do passado. Para o direito, a palavra proferida pelo tribunal é reparatória e retributiva, em termos quase econômicos, assumidos péla possibilidade de reverter o passado através do ato punitivo. Na visão dos juristas, a justiça da pena estaria na função de anamnésia que ela pode exercer, trazendo ao presente o mal passado com a finalidade de verificar a importância da pena e evitar a repetição (MEYER, 2012, p. 40). Nesse sentido, François Ost (1999) sustenta que aos danos da 
destemporalização (desordenação do tempo) imposta por Estados e situações de rupturas de regimes políticos, o direito oferece formas de retemporalização (ordenação do tempo) que permitem estabilizar o passado. Esta também é uma proposta de ordenação do tempo, que consiste na reversão das injustiças históricas através da justiça:

Não possuímos ferramentas empíricas para analisar neste momento os ganhos e perdas de cada política do tempo. Mas, podemos afirmar com clareza que há algo de incompatível entre o que o nosso mundo e o nosso presente esperam da história, e o que os historiadores e a historiografia podem, diante destas considerações, oferecer. Nos últimos anos, quando os mecanismos de justiça de transição $0^{6}$ recorrem à história, o fazem de forma a subverter sua própria ontologia: ela é usada como forma de

6 Diversas são as definições para justiça de transição, assim como diversas são as experiências de justiça de transição em países que realizam medidas e ações para responder ao passado que não passa, ao passado marcado pela violência institucionalizada pelo Estado e por guerras civis. Somente em 2003, o Conselho de Segurança da Organização das Nações Unidas (ONU) conceituou justiça de transição em nível supranacional, como "o conjunto de medidas e mecanismos associados à tentativa de uma sociedade de lidar com o legado de abusos em larga escala do passado, buscando assegurar a legitimidade (accountability), justiça e reconciliação". Além do posicionamento do Estado de recontiecer, reparar, reformar-se institucionalmente e não deixar lacunas à impunidade, compõem estes processos diversos atores da academia e da sociedade civil, como sobreviventes, familiares e organizações de direitos humanos (MEYER, 2012, p. 244). aprisionar o passado que, para mortos, desaparecidos, sobreviventes, familiares e sociedade é existência.

\section{Historiografia e Justiça de Transição: um intercâmbio necessário}

"O discurso sobre a memória veio para ficar, diagnostica Andreas Huyssen (2014, p. 140). Em paralelo à hipertrofia da história, combatida por Friedrich Nietzsche no século XIX, Huyssen parece reprovar a hipertrofia ou obsessão por memória nas sociedades ocidentais contemporâneas. Vivenciamos uma nova ordem do tempo ou, como prefere François' Hartog (2013), um novo regime de historicidade, em que o presentismo extingue o sentido de passado e de futuro como fronteiras bem delimitadas do espaço histórico. Ao mesmo tempo, a história como conhecimento sobre a relação entre as categorias temporais também é esvaziada de sentido. Tanto Huyssen como Hartog, apesar das diferenças de abordagem, têm argumentado sobre o papel do historiador como mediador 
da reordenação do tempo, através de uma redefinição do olhar distanciado da história. Mas esta é apenas uma das trilhas seguidas pelos tortuiosos caminhos de busca e transformação epistemológica na historiografia pós justiça transicional.

Em última instância, esses caminhos são produzidos por duas indagações: para quem serve a história? O que queremos quando escrevemos história? A primeira pergunta nos permite alcançar alguns desdobramentos: a história serve às querelas internas do meio acadêmico, do debate especializado de intelectuais que observam o mundo de um lugar privilegiado; ou, de alguma forma, a história serve ao mundo dos vivos, sendo assim útil ao presente?

Dos diversos estudos históricos produzidos nos últimos anos, especialmente sobre os passados traumáticos, os da história profissional são os menos requisitados e revisitados na esfera pública. Esta admissão pode ser explicada por dois caminhos: pelo fato de, por um longo período, a historiografia ter se preocupado com a legitimidade científica tendo ficado circunscrita às categorias da razão e da consciência histórica; e/ou, conforme salientado há tantos anos por Martin Heidegger, (apud ALMEIDA, 2014, p. 63), devido "à irresponsabilidade social e política disfarçada de neutralidade acadêmica e autonomia dos historiadores. Na mesma direção, Tzvetan Todorov (2002) problematiza que, ao refletir sobre seu trabalho, geralmente este grupo de intelectuais não enxerga a si mesmos como agentes sociais. Fatores que explicam o isolacionismo da comunidade historiadora no rol de autores de estudos históricos que reverberam suas representações para além das fronteiras da academia?.

Nos últimos anos, o fascínio pelo passado gerado pelas experiências violentas do sécullo XX não foi acom-

\footnotetext{
7 Alexandre Avelar (2015), refletindo sobre o processo em curso de indisciplinarização da História, ressalta a pesquisa realizada em 2013, por Sabina Loriga, pela qual a autora analisa como os historiadores são representados em 20 romances publicados entre 1872 e 2010. Após examinar obras tão distintas, a autora conclui que prevalece uma imagem pejorativa em três tipos principais de personagens: o erudito completamente imerso no passado, não preocupado com o mundo dos vivos; o intelectual submetido às manipulações da esfera política; o historiador absorvido pela fugacidade do passado e preocupado em demonstrar "a inacessibilidade das experiências humanas pretéritas" (AVELAR, 2015, p. 05). A argumentação de Avelar nos faz refletir: se a indagação feita pela autora fosse transportada para o recorte deste trabalho, como seriam representadose quais tipos de críticas seriam remetidas a historiadores, por outros produtores de discursos históricos, diante de processos de justiça de transição?
} 
panhado pela crença de que seria possível aprender com a história ou com a historiografia. Hans Ulrich Gumbrecht (2011, p. 26) diagnosticou esse processo no que ele definiu como progressiva perda da capacidade orientadora da história. Diante desse quadro, alguns historiadores vêm se debruçando sobre questões que envolvem o que esperamos e desejamos da história que escrevemos. O que, em última medida, corresponde a estudar o tempo histórico em profundidade.

Berber Bevernage (2014a) vem apontando em seus trabalhos para a importância de se pensar na reordenação do tempo, não apenas dentro dos limites epistemológicos atuais da disciplina, mas de forma a abarcar o processo mais amplo que envolve atores e ações relacionadas a sociedades que enfrentam seu passado recente. Esta consideração nos leva ao entendimento de uma premissa importante: a história não é a única narrativa capaz de colocar ordem no tempo, como nos orienta Hartog (2013). Mas, ela teria condições próprias de agir nessa ordenação de formá compartilhada com outros discursos. As formas desta contribuição estão primordialmente fun- damentadas no estado de verdade que as reivindicações históricas assumem na cena pública quando são supervisionadas por especialistas, quando são demarcadas pelo lugar de fala que possui autoridade na análise do tempo. Em outras palavras, sobre como a narrativa dos historiadores são fontes do estabelecimento de um regime de inscrição sobre o passado na memória públicå.

A possibilidade desta cooperação vincula-se ainda a dois fatores também salientados por Bevernage: primeiro, diante do dever de memória que convulsiona o mundo contemporâneo, o caráter imoral do tempo irreversível da história; segundo, o entendimento da necessária virada performativa do conhecimento histórico. Procurando extrapolar as concepções dicotômicas entre presença e ausência do passado, entre tempo da justiça e tempo da his-

8 Mas, não dá.para pararmos por aqui. Vemos a importância desse discurso de autoridade - mesmo que não defendamos uma postura arrogante de hegemonia do discurso histórico - mas há algo mais profundo ao se pensar na importância da inserção do olhar historiográfico de forma horizontal em relação ao mundo. Não há como pensarmos em qualquer instância de autoridade da historiografia, mesmo que para falar do seu objeto primordial de estudo, sem primeiro problematizarmos a publicização da história. Em outros termos, é difícil refletir sobre o que acreditamos que seria a contribuição singular da historiografia para a justiça de transição se não pensarmos primeiro a quem nos dirigimos e o que esse público espera de nós. 
tória, Bevernage constrói uma cronosofia alternativa. À fugacidade do irreversível, ele contrapõe a teimosia do irrevogável-teimosia que não compreende a reparação. O passado é passado e não pode ser alterado. Isso é indiscutível para o autor. Mas, há a permanência de suas manifestações, que teimam a espreitar 0 presente? Como bem explica Alexandre Avelar (2015, p. 07), "o tempo irrevogável desafia a rigidez das categorias de ausência e presença pela reivindicação de uma completa e aparentemente contraditória presença do que é geral-

9. Há algo de extremamente inovador e importante na perspectiva de Bevernage: ele fornece justificativas pertinentes para a performatividade da história, não como uma "traição" à comunidade intelectual, mas uma fidelidade ao humano. Todavia, há algo de primitivo, basilar, nessa consideração, que remonta aos escritos de Michel de Certeau, conforme citado em Dosse (2013, p. 179): "um acontecimento não é o que é possível ver ou saber dele, mas aquilo em que ele se tornará (e sobretudo para nós)". Há um sentido sempre aberto no acontecimento, para Certeau, pois são os vestígios deixados por ele que deve importar ao historiador. Quanto a passados traumáticos, processos históricos transladados por nós de temporalidades, a lógica parece ser a mesma. mente considerado ausente, o passado". O desenvolvimento de uma prática historiográfica alternativa, nos moldes como um grupo de historiadores e historiadoras vêm pensando, depende da recusa de uma deontologia que absorve o tempo como uma flecha, um singular coletivo devorador das experiências.

Na trilha das novas propostas de relação com o tempo, o envolvimento do historiador como ator que assume o papel de cidadão tem gerado propostas que desorganizam a concepção tradicional do observador imparcial ${ }^{10}$. Para Bevernage (2013), no contexto em que o tempo histórico é ameaçado pelo irrevogável, a história adquire um atributo que an-

10 Lorenz e Bevernage (2013) salientam que a questão da imparcialidade não se sustenta nem mesmo no saber produzido por aqueles que a defendem de forma intransigente. Para os autores, a própria escolha dos historiadores em debruçar-se sobre eventos ou estruturas vai além de um jogo entre dois modos de temporalização. É uma definição que tem consequências estéticas, éticas e políticas. 
tes era inimaginável. Ela torna-se reguladora da distância temporal. Em vez da distância entre passado e presente, vista como naturalmente construídà, ela é ativamente construída, por meio de ideologias e afetos. Nestes termos, em vez de contemplativa, a história precisa ser performativa. Além de descrever a realidade, ela pode produzir efeitos sociopolíticos a partir da linguagem e de outras formas de ação. A historiografia, assim, pode produzir sentido para nosso presente. E o historiador pode assumir uma responsabilidade social enquanto dimensão moral do saber histórico. De forma mais radical, a contestação epistemológica e deontológica induzida pelas transformações sociais de relacionamento com o tempo, esboça uma espécie de historiador eticamente responsável que, ao mesmo tempo, implica o fim de um certo tipo de historiador (JENKINS, 2004).

\section{Confrontando o passado recente na cena pública: a atuação de historiadores na América Latina}

Augu'sto Pinochet foi preso em Lon- dres, em 1998, por ordem do juiz espanhol Baltasar Garzón, apoiado no princípio da jurisdição universal sobre crimes de genocídio e contra a humanidade. Da prisão, o ditador acusado por trezentos crimes, escreveu uma carta ao povo chileno, na qual defendia que a intervenção ditatorial dos militares no Chile foi um gesto heroico de servidão à pátria. Era uma das verdades históricas expressas na carta. E a legitimação da verdade vinha providencialmente vinculada ao discurso especializado em proferi-la. Dizia: "nenhum historiador, nem mesmo o mais tendencioso e não objetivo, pode e nem poderá um dia sustentar de boa fé que minhas atuações públicas responderam a uma suposta ambição pessoal ou a qualquer outro motivo que não o bem do Chile".

Pinochet deliberava, para além de suas verdades históricas, sobre o que é ser historiador: imparcial, objetivo e detentor da última palavra sobre o que de fato aconteceu. Definir o papel do historiador no mundo e utilizar da autoridade do nosso discurso para falar do tempo, em contextos que pedem por história como estabilizadora do passado e do presente, não parece ser exclusivo do discurso de perpetradores de gra- 
ves violações de direitos humanos. Em 2004, diante das "descomemorações" do golpe de 1964 no Brasil, o porta-voz da Presidência da República transmitiu a seguinte mensagem do então presidente, Luís Inácio Lula da Silva: "Devemos olhar para 1964 como um episódio histórico encerrado. O povo brasileiro soube superar o autoritarismo e restabelecer a democracia no país. Cabe, agora, aos historiadores fixar a justa memória dos acontecimentos e personagens daquele período" (Cf. BAUER, 2013, p. 18). Lula, através deste pronunciamento, enterrava o passado, fechava o tempo da espera, que é o tempo dos sobreviventes e familiares, tornava o acontecimento irreversível e irreparável. A responsabilidade toda de lidar com esse passado recaía, assim, sobre os ombros dos historiadores: guardiões da verdade de um tempo que não existe mais.

Em alguma medida, estas demarcações são prognósticos de como agem historiadores em relação aos mecanismos da justiça de transição. Vejamos, por exemplo, esse itinerário em alguns países da América Latina.

A Argentina foi o primeiro país a enfrentar a violência ditatorial através da memória e da verdade. Em 1983, foi criada a Comisión Nacional sobre la Desaparición de Personas (CONADEP), para investigar as graves violações de direitos humanos ocorridas no período entre 1976 e $1983^{11}$. O resultado dos trabalhos foi apresentado no relatório Nunca Más, uma tentativa exaustiva de retomar fatos e dados quantificáveis, que convocava a teoria dos dois demônios e encerrava o passado de conflitos, para tornar possível certa reconciliação nacional12.

No caso argentino, o Nunca Más reverberou com grande relevância e popularidade na sociedade ${ }^{13}$, mas esse

11 Cabe ressaltar que a Bolívia foi o primeiro país a estabelecer uma comissão da verdade na América Latina, em 1982, mas não concluiu seus trabalhos após três anos de exercício (HAYNER, 2002).

12 Conforme Gabriela Águila (2012), o relatório Nunca Más antes de tudo se estabeleceu como uma ode ao silêncio, estendida também ao ambiente acadêmico. A convocação da teoria dos dois demônios - que, ao mesmo tempo que reconhecia os crimes cometidos pelo Estado, afirmava que a ditadura tinha sido produto de um conflito entre dois lados com responsabilidades iguais - propiciou a hegemonia de discursos que condenavam em massa o estudo do passado recente.

13 Apesar do apoio de organizações de direitos humanos ao Nunca Más, muitas são as críticas à sua tentativa de encerrar ali o passadó em prol da reconciliação nacional. A mais contundente vem das Madres da Plaza de Mayo, que condenam a expressão do passado morto, inferior ao presente vivo. As Madres defendem radicalmente o passado como existência, sua presença viva até que a justiça seja possível. Em vez de Nunca Más, esperança se transforma em luta na defesa do Aparición con vida, assim definido por Hebe Bonafini, líder do grupo: "Sabemos o que se passou Não estamos loucas, não pedimos coisas impossíveis. Aparición cóm vida é principalmente uma expressão ética. Enquanto todos os assassinos não estejam presos, nossos filhos viverão para condená-los". [Sabemos lo que pasó. No estamos locas, no pedimos cosas imposibles. Aparición con vida es principalmente una consigna ética. Mientras uno solo dos asesinos permanezca em las calles, nuestros hijos vivirán para condernalos] (BEVERNACE, 2014, p. 91 , traduzido pela autora). 
processo não foi acompanhado pela produção historiográfica, salvo algümas exceções. A distância temporal como indispensável para a análise histórica foi justificativa para o posicionamento dos historiadores argentinos somente anos depois da divulgação do relatório. Luis Alberto Romero, influente acadêmico, sustentou em uma nota à imprensa em 1996: "A história termina há cinquenta anos atrás; o que vem depois é política. A história deve ater-se aos fatos, ao realmente ocorrido; o resto é filosofia" (Cf. ÁCUILA, 2012, p. 66).

Nas últimas décadas, a historiografia tem enfrentado cada vez mais esse passado traumático. Marina Franco e Florencia Levín (2007) identificam que a história do tempo presente encontra-se em amplo processo de expansão e institucionalização no país. Mas, na medida em que se ampliam a gama de profissionais voltados a analisar o período de 1976 a 1983 , os conflitos éticos dentre discursos e conceitos se acirram, tornando-se uma questão de ordem política.

Na Argentina, intensos, questionamentos são feitos em torno da utili- zação de categorias como guerra civil, processo, ditadura, e terrorismo estatal para caracterizar o governo militar. Discussão que se torna ainda mais conflituosa quando o termo genocídio aparece no rol das representações. A inadequação do conceito para caracterizar a ditadura argentina vem sendo sustentada há muitos anos pela socióloga Silvia Sigal (2001), cuja interpretação é veementemente rechaçada por organismos de direitos humanos. Franco e Levín (2007) ressaltam que o conflito com os historiadores emergem principalmente do uso impreciso do termo guerra civil para delimitar a luta das organizações de esquerda armada contra as forças do Estado.

Apesar da difícil relação entre história e justiça de transição, em 2015, historiadores argentinos invadiram a cena pública para se posicionarem contra intervenções que relativizavam os crimes da ditadura e questionavam os julgamentos de agentes do Estado, ocorridos logo após a eleição de Maurício Macri. Declarando-se como investigadores da história recente e também como cidadãos, este grupo observou o mundo de forma horizontal. Rompendo Ao romperem com a tradicional autonomia reivindicada pela 
historiografia perante a sociedade, tornaram-se atores envolvidos politicamente no enfrentamento deste passado. Todavia, existiam duas defesas em seu discurso que demarcam - lugar de fala da história: primeiro, a alegação de que a defesa da justiça de transição não significava considerar que a verdade dos tribunais era única, última e esgotava o passado; segundo, devolvia à história a capacidade orientadora de iluminar o passado. A declaração, nos moldes de um manifesto, abre uma fenda no fascínio pelo passado para demarcar que é possível e necessário aprender com a história ${ }^{14}$.

No Chile, uma reação semelhante havia ocorrido após a publicação da Carta aos chilenos (PINOCHET, 1998). Combatendo as declarações de Pinochet, os historiadores assumiam uma

14 Conforme a declaração: "Estas ideias formam parte do nosso compromisso como investigadores da história recente do país, mas também como cidadãos que entendem que o conhecimento da história argentina recente continua sendo uma ação necessária para iluminar este passado que, por suas qualidades, ainda interpela nossa sociedade. Também porque compreendemos que nele se expressa nossa disposição com a vigência presente e futura dos direitos humanos". [Estas ideas forman parte de nuestro compromiso como investigadores de la historia reciente del país pero, también, como ciudadanos que entendemos que el conocimiento de la historia argentina reciente continúa siendo una empresa necesaria para iluminar este pasado que, por sus cualidades, nos sigue interpelando como sociedad y porque comprendemos que, en ello, se expresa nuestra voluntad para con la vigencia presente y futura de los derechos humanos] (ADHILAC, 2015, traduzido pela autora). posição frente ao seu presente, condenando aquilo que chamaram de anti-história. No Manifiesto de historiadores, o papel normativo da história também é reclamado: "A história não se ocupa somente do passado, mas também, e principalmente, do presente e do futuro. A história é projeção. É a construção social da realidade futura" (MANIFIESTO DE HISTORIADORES, 1999) ${ }^{15}$. E este papel estaria ainda atrelado à demanda social.

No Brasil, os avanços da justiça transicional geram debates cada vez mais acirrados entre os historiadores. A criação da Comissão Nacional da Verdade (CNV), em 2011, trouxe à cena pública diferentes posicionamentos sobre envolver-se ou não com a história comissionada'. De um lado, a postura de Carlos Fico, historiador com grande experiência na história recente brasileira, foi epistemologicamente rígida. Não aceitou compor o quadro dos comissionados da CNV sob justificativa de que não há história única, absoluta e que determina uma verdade metafísica. Fico assume que não há

15 [La historia no es sólo pasado; sino también, y principalmente, presente y futuro. La historia es proyección. Es la construcción social de la realidad futura] (MANIFIESTO DE HISTORIADORES, 1999, traduzido pela autora). 
possibilidade da história trabalhar nos moldes da justiça de transição. Tradicionalmente, sua posição é defendida pela historiografia.

De outro, historiadores que participaram dessas iniciativas demarcaram um novo espaço para a história. Daniel Faria (2014), professor do Departamento de História da Universidade de Brasília, foi membro da Comissão Anísio Teixeira e, ao relatar sobre os encaminhamentos dos trabalhos da comissão, observou o questionamento constante sobre o uso da palavra verdade. Aqui há também uma contestação no sentido de verdade última, metafísica. Mas, não é dessa verdade que se trata, no seu entendimento. Ele argumenta que nossa própria língua admite definições mais modestas para a palavra: "preencher lacunas que encobrem os destinos que foram dados a vidas, desfazer mentiras, confrontar-se com a ocultação astuciosa de informações, encontrar pistas e vestígios que esclareçam nossa história, almejar a veracidade" (FARIA, 2014). Para Faria, há uma urgência ética e política que impõe ao historiador não se dissociar do papel de cidadão. Nesses termos, a defesa é pela historiográfia alternativa, pela qual nosso trabalho compreende o quanto nos envolvemos com o mundo, o quanto o presente nos afeta.

Além de posicionamentos individuais, na relação com outros profissionais certas abordagens historiográficas têm sido rechaçadas pela aproximação (e legitimação) do discurso dos perpetradores de violações de direitos humanos durante a última ditadura. Narrativas que defendem a existência de um acordo político para explicar a transição brasileira são ainda recorrentes na historiografia, mesmo diante dos protestos de grupos que sofreram diretamente com a violência do Estado, organizações de direitos humanos, juristas, cientistas políticos e até mesmo de alguns historiadores ${ }^{16}$. No mesmo caminho, análises históricas mais recentes, que parecem relativizar

16 Emílio Péluso (2013) questiona a explicação histórica do acordo político, utilizada para dar legitimidade aos votos do Supremo Tribunal Federal, em 2010, na votação da ADPF 153, pela revisão de Lei de Anistia: "A questão é a seguinte: quem seriam as partes desse acordo? Como um governo autoritário assinaria um acordo com a oposição? Como seria possível tal acordo se, em 1979, boa parte da oposição armada já havia sido fulminada? O fato é que, diante da Constituição de 1988 - democrática e afirmadora de direitos humanos - o STF preferiu dar validade a um sentido de uma lei imposta durante a ditadura, permitindo que permaneçam impunes agentes públicos responsáveis pelos mais atrozes atos praticados com o uso do Estado. Disse mais o Supremo: tal acordo seria tão importante que, inclusive, estabeleceria as bases da Constituição de 1988-o que significa que, em última instância, apenas uma nova Constituição permitiria discutir os termos da anistia". 
a violência da ditadura brasileira, seja por identificar o trauma social com a frustração que a anistia promoveu diminuindo a responsabilidade dos agentes do Estado - seja por questionar que o regime ditatorial tenha sido de fato uma exceção na cultura política nacional, têm sido combatidas ${ }^{17}$. Tais afirmativas, respaldadas pela imparcialidade da observação histórica, são análogas às justificativas utilizadas por agentes do Estado quando confrontados em audiências públicas.

Extrapolando as experiências mais conhecidas, a relação entre historiografia e justiça de transição parece tomar outros contrastes na Guatemala. O relatório final da Comisión para el Esclarecimiento Histórico (CEH) foi divulgado em 1999. Diante do contexto político e social do país, marcado por divisões profundas que solapavam tanto a possibilidade de curar as feridas do passado, quanto de construir a paz no futuro, a comissão optou por interpretar não apenas a guerra e o golpe de 1954, mas as causas sistêmicas da violência do Estado. Memórias del si-

17 Aqui se incluem trabalhos de historiadores influentes, como Carlos Fico $(2010 ; 2012)$ e Daniel Aarão Reis Filho (2010; 2014). lencio, diferentemente de relatórios de outras comissões latino-americanas, tem sido considerado como uma aná-, lise histórica estrutural para entender o passado recente e o presente do país (GRANDIN, 2014). Através do que define como visão e metodologia histórica, Greg Grandin sustenta que somente a partir desta abordagem, em contraposição ao enfoque na memória das demais comissões que a precederam, a comissão guatemalteca foi capaz de afirmar que os militares haviam cometido atos de genocídio, justificando a existência de crimes de natureza coletiva envolvendo o Estado. Para Grandin (2014, p. 50),

Como outras comissões da verdade, a Comissã̃o para o Esclarecimento Histórico utilizou uma variedade de métodos para abordar o passado [...] Mas, sua importância e legado residem na segurança e lúcidez de suas conclusões históricas. Essa solidez interpretativa, ao contrário dos temores de intelectuais da Justiça de Transição, não encerrou o debate quanto ao passado da Guatemala, e sim fortaleceu, mesmo que de forma inicial, aqueles que lutam por definir o seu futuro.

Nos termos do autor, o reconhecimento da história comissionada está 
atrelado ao discurso legítimo e à autoridade do conhecimento histórico. Metodologia que concede segurança elucidez à narrativa. Como se (e niovamente) curvar-se à Clio significasse assumir um patamar superior no mundo, pelo qual este seria transformado no soar de uma trombeta. Nada de (muito) novo nas formas de conceber como se reordenar o tempo.

\section{Considerações finais}

Não há dúvidas de que os crimes do século XX instituíram algo de singular e excepcional ${ }^{18}$. Na batalha de representações do passado recente, muito se discute sobre a impossibilidade de reconstruir o inenarrável; ou sobre a

18 Aqui é necessário que se faça um mea-culpa. Durante todo o artigo, há uma tentativa de evitar caracterizar o passado recente latino-americano através da categoria de trauma, tão referenciada no século $X X$, devido à dimensão dupla $e$ ambígua da mesma. Trauma é presença do passado congelado no presente. Trauma é também ausência, no exato momento em que a narrativa institui uma quebra entre o que foi experenciado no passado e o que é elaborado e simbolizado no presente. Nossa argumentação foi desenvolvida justamente para demonstrar a inviabilidade de quebras no tempo, de se opor a categorias normativas do tempo histórico que não são capazes de dimensionar permanências e performatividades do passado recente. Mas essa afirmação final nos remete a uma fraqueza epistemológica: a unicidade referida provém da percepção historiográfica, que, em última instância, é uma representação. incapacidade ontológica, entre objetividade e subjetividade, de dar sentido ao injustificável. A centralidade de eventos como a Shoa e as experiências autoritário-repressivas na América Latina, introduzem o que Rodrigo Patto Sá Motta (2011, p. 91) denomina como "uma espécie de grau zero de facticidade, ou seja, um acontecimento cuja realidade não pode ser negada". Acontecimentos cuja presença espectral avalia constantemente as suas interpretações no presente. Atualmente, as novas preocupações de reinserir o acontecimento na historiografia o compreendem, ao mesmo tempo, como decorrência e como ruptura, "como desfecho e como abertura de possíveis" (DOSSE, 2013, p. 6).

Entre guerras de memórias e embates entre memória e história, o caráter flutuante dos usos do passado emerge e repercute por diversos lugares de fala e políticas do tempo. A historiografia progressivamente perde espaço e sentido diante desse mundo. Há o fator, já identificado por Huyssen (2014), de obsessão por memória que os crimes do século XX engendraram. Mas há, e este é o ponto principal de nossa preocupação, algo intrínseco ao nosso campo, sobre 
as formas de escrever a história e sobre como podem agir os historiadores. 0 debate em torno destas questões vem crescendo dentro da historiografia e propostas importantes de transformações epistemológicas e deontológicas têm ganhado espaço. Começa a surgir (ou ressurgir) o entendimento de que a história molda o mundo. Assim, há um dever do historiador de atuar sobre seu presente considerando todas as implicações políticas e sociais de suas atitudes, pautado no que o torna um especialista.

Se hoje a historiografia perde sentido frente ao crescente fascínio pelo passado, muitas vezes suprido pela história não acadêmica, não podemos
Mas há, e este é o ponto principal de nossa

preocupação, algo intrínseco ao nosso campo, sobre as

formas dé escrever a história e sobre como podem agir os historiadores. 0 debate em torno destas questões vem crescendo dentro da historiografia e propostas importantes de transformações

epistemológicas e deontológicas têm ganhado espaço. Começa a surgir (ou ressurgir) o entendimento de que a história molda o mundo. Assim, há um devẹr do historiador de atuar sobre seu presente considerando tódas as implicações políticas e sociais de suas atitudes, pautado no que o torna um especialista. nos isentar de responsabilidade nesse processo. Em grande, medida, a ausência da história nos processos de justiça de transição provoca a utilização e reverberação de conceitos e análises estranhas ao que discutimos há muitos anos na academia. Mesmo esta relação, quando existe, é do alto de um discurso de autoridade sobre o tempo, que conduz cada vez mais ao isolamento, em contextos que clamam por intercruzamento é compartilhamento de análises e ações. Há espaço, há reivindicação e há necessidade de história. Mas, entre o velho, o atual e o inédito na historiografia, precisamos reformular aquela velha questão: para quem serve a história? 


\section{Referências}

ÁGUILA, C. La historia reciente en la Argentina: um balance. Historiografias, n. 3, p. 67-76, jan./jun. 2012

ALMEIDA, G. Futuro e história: análise da temporalidade atual. História da historiografia, Ouro Preto, n. 15, p. 51-69, ago. 2014. doi: http://dx.doi.org/10.15848/hh.v0i15.736

ADHILAC (Asociación de Historiadores Latino-americanos y del Caribe). La democracia se construye con verdady con justicia. Declaracion de historiadores argentinos [S.I., online]. 2015. Disponível em: <http:/I adhilac.com.arl?p=11187>. Acesso em: 5 jul. 2016.

ASSMANN, A. Transformations on modern time regimes. In: BEVERNACE, B.; LORENZ, C. (Orgs.) Breaking up time: negotiating the borders between present, past and futures. Cöttingen: Vandenhoeck and Ruprecht, 2013. p. 39-56.

AVELAR, A.. Rumo à indisciplinarização? Tempo histórico e a historiografia recente sobre o período militar. In: ENCONTRO A HISTÓRIA (IN)DISCIPLINADA. Teoria, ensino e difusão do conhecimento histórico, 1., 2015, Porto Alegre. [Comunicação oral]. Universidade Federal do Rio Grande do Sul, 2015.

BAUER, C. O papel dos historiadores na garantia dos direitos à memória, à verdade e à justiça. Aedos, Porto Alegre, v. 5, n. 12, p. 6-24, jan./jul. 2013.

BEVERNACE, Berber. Time, Presence, and Historical Injustice. History and Theory, Connecticut, v. 47, n. 2 , p. 149-167, maio 2008

Transitional justice and historiography: challenges, dilemmas and possibilities. Macquarie Law Journal, Sidney, v. 13, p. 7-24, 2014a. Disponível em: <http://hdl.handle.net/1854/LU-5765503>. Acesso em:jan. 2017.

Historia, memoria y violencia estatal: tiempo y justicia. Buenos Aires: Prometę, $2014 b$

BEVERNACE, Berber; LORENZ, Chris. Breaking up time: negotiating the borders between present, past and future - an introduction. In: (Orgs.). Breaking up time: negotiating the borders between present, past and future. Cöttingen: Vandenhoeck and Ruprecht, 2013. p. 7-36.

BONASSI, F. Prova contrária. Rio de Janeiro: Objetiva, 2003.

BLOCH, M. Apologia da História ou o Ofício do. Historiador. Rio de Janeiro: Jorge Zahar, 2001

CHALHOUB, Sidney. A crise atual, Machado de Assis e a história como hiper-ficção. Sul 27 [online], abr. 2016. Disponivel em: <http://www.sul21.com.br/jornal/a-crise-atual-machado-de-assis-e-a-historia-como-hiper-ficcao-por-sidney-chalhoub>. Acesso em: 21 abr. 2016.

DOSSE, F. Renascimento do acontecimento: um desafio para o historiador. Entre Esfinge e Fênix. São Paulo: Unesp, 2013. 
FARIA, Daniel. Sobre a Comissão Anísio Teixeira. UnB Agência, Brasília, 27 maio 2014. Disponível em: <http://unb2.unb.br/noticias/unbagencia/artig.o.php?id=718>. Acesso em: 10 jun. 2016

FICO, C. A negociação parlamentar da anistia de 1979 e o chamado perdão aos torturadores. Revista Anistia Política e Justiça de Transição, Brasília, p. 318-333, 2010. [Comissão de Anistia]

História do tempo presente, eventos traumáticos e documentos sensíveis: o caso brasileiro. Varia História, Belo Horizonte, v. 28, n. 47, p. 43-59, jan./jun. 2012. Disponível em: <http://www.scielo. br/pdf/vh/v28n47/03.pdf>. Acesso em: jan. 2017

FRANCO, M.; LEVÍN, F. El pasado cercano en clave historiográfica. In: Historia reciente. Perspectivas y desafíos para un campo en construcción. Buenos Aires: Paidós, 2007. p. 31-55.

GARAPON, A. Crimes que não se pode punir nem perdoar. Para uma justiça internacional. Lisboa: Instituto Piaget; Minerva, 2004.

GIRALDO, Manuel Lucena. Historia pública: ¿Una fatalidad historiográfica? El público, lo público y la. historia que publico: História da Historiografia, Ouro Preto, n. 20, p. 191-201, abr. 2016. Entrevista concedida a César Augusto Duque Sánchez.

GRANDIN, G. A instrução da grande catástrofe: Comissões da Verdade, história nacional e formação do Estado na Argentina, Chile e Guatemala. Tradução de Ana Paula Meyer Velloso. Ponto-e-Vírgula-Revista de Ciências Sociais, [S.I.], n. 15, abr. 2015. ISSN 1982-4807. Disponível em: <https://revistas.pucsp.br/index.php/pontoevirgula/article/view/22559>. Acesso em: jan. 2017.

CUMBRECHT, H. Depois de Depois de aprender com a história, o que fazer com o passado agora? In: NICOLAZZI, F.; MOLLO, H.; ARAÚJO, V. Aprender com a história? O passado e o futuro de uma questão. Rio de Janeiro: FCV, 2017. p. 25-42.

HAYNER, P. Unspeakable truths: confronting state terror and atrocities. New York: Routledge, 2002.

HARTOG, F. Regimes de historicidade. Presentismo e experiências do tempo. Belo Horizonte, MG: Autêntica, 2013. (Coleção História e Historiografia).

HUYSSEN, A. Culturas do passado-presente: modernismos, artes visuais e políticas de memória. Rio de Janeiro: Contraponto; Museu de Arte do Rio, 2014.

JENKINS, K. Ethial responsibility and the historian: on the posible end of a history "of a certain kind". History and Theory, [S.I.], v. 43, n. 4, p. 43-60, dez. 2004. Disponível em: <http://www.jstor.org/stable/3590635>. Acesso em: jan. 2017.

KOSELLECK, R. Estratos do tempo: estudos sobre história. Rio de Janeiro: Contraponto; PUC Rio, 2014.

MANIFIESTO DE HISTORIADORES. Santiago de Chile, jan. 1999. Disponível em: <http://www.archivochile.com/Ceme/recup_memoria/cemememo0003.pdf>. Acesso em: 1 jul. 2016.

MANIFESTO DO CLUBE MILITAR: vídeo sobre verdade histórica e Comissão Nacional da Verdade. Vídeo produzido por Carlos Fico. Disponível em: https://snhhistoriografia.wordpress.com/page/2/. Acesso em 15 de junho de 2016. 
MEYER, E. P. N. Ditąura e responsabilização: elementos para uma justiça de transição no Brasil. Belo Horizonte: Arraes, 2012.

O debate atual sobre a Lei de Anistia. Revista Coletiva, [S.I.], n. 12, p. 1-3, set./dez.2013. ISSN 2179-1287. Disponivel em: <http://www.coletiva.org/index.php/artigo/o-debate-atual-sobre-a-lei-de-anistia-no-brasil/>. Acesso em: jan. 2017.

MOTTA, R. P. S. Pesquisar experiências autoritário-repressivas recentes: dilemas e riscos. In: NICOLAZZI, F., MOLLO, H.; ARAÚJO, V. Aprender com a história? O passado e o futuro de uma questão. Rio de Janeiro: FGV, 2011. p. 91-111.

OST, François. OTempo do Direito. Portugal: Instituto Piaget, 1999. (Coleção Direito e Direitos do Homem).

PEREIRA, M; SANTOS, P. A. C. Mutações do conceito moderno de história? Um estudo sobre a constituição da categoria "Historiografia Brasileira" a partir de quatro notas de rodapé (1878-1951). In: SILVA, A. R. C.; NICOLAZZI, F.; PEREIRA, M. (Orgs.). Contribuições à história da historiografia luso-brasileira. São Paulo: Hucitec; Belo Horizonte: Fapemig, 2013. p. 1-47.

PINOCHET, Augusto. Carta a los chilenos, dez. 1998. Disponível em: <https://es.wikisource.org/wiki/ Carta_a_los_Chilenos, de_Augusto_Pinochet>. Acesso em: 5 jul. 2016.

REIS FILHO, D. A. Ditadura, anistia e reconciliação. Estudos Históricos, Rio de Janeiro, v. 23, n. 45, p. 171$186,2010$.

A ditadura faz cinquenta anos: história e cultura política nacional-estatista. In: REIS FILHO, D. A. et al. (Orgs.). A ditadura que mudou o Brasil: 50 anos do golpe de 1964. Rio de Janeiro: Zahar, 2014. p. 11-29.

SICAL, Silvia. La polémica sobre el genocidio. Puentes, v. 2, n. 5, p. 62-65, 2011.

TODOROV, T. Memoria del Mal, Tentación del Bien: indagación sobre el siglo XX'Trad. Manuel Serrat Crespo. Barcelona: Península, 2002.

WHITE, Hayden. The Practical Past. Historein, [S.I.], v. 10, p. 10-19, maio 2011. ISSN 2241-2816. Disponível em: <https://ejournals.epublishing.ekt.gr/index.php/historein/article/view/2094/1934>. Acesso em: jan. 2017. doi: http://dx.doi.org/10.12681/historein.2 